\title{
WHAT DOES A GASTROENTEROLOGIST NEED TO KNOW IN THE TIME OF SARS-CoV-2 PANDEMIA?
}

DOI: 10.36740/WLek202004101

\author{
Peter Christopher Konturek, Igor Alexander Harsch \\ THURINGIA-CLINIC SAALFELD, TEACHING HOSPITAL OF THE UNIVERSITY OF JENA, GERMANY
}

\begin{abstract}
Coronavirus disease 2019 (COVID 19) is an emerging infectious disease caused by a novel coronavirus SARS-CoV2 that was first identified in Wuhan, China 2019 and that led to a worldwide pandemia. In addition to typical respiratory signs (dry cough, shortness of breathing), some patients may develop gastrointestinal and hepatological complications including diarrhea or acute hepatitis, respectively. Due to the close contact to the patient's secretion, the gastroenterologists are at increased risk of getting the infection. Therefore, a proper individual risk stratification before every endoscopic procedure is highly recommended. Endoscopy personnel should reduce exposure hazards by keeping a distance from the patient and using gloves, face masks, face shields and gowns. Taking into the consideration the fact that the virus proliferates in the gastrointestinal (GI) tract, special attention should be given to handling with stool specimens. In patients obtaining FMT for recurrent C. difficile infection, recommended screening measures include donor's medical history and testing for SARS-COV-2 presence in pharyngeal and stool specimens.
\end{abstract}

KEY WORDS: SARS-CoV-2, digestive system, endoscopy

Wiad Lek. 2020;73(4):625-628

\section{INTRODUCTION}

Coronavirus disease 2019 (COVID 19) is an emerging infectious disease caused by a novel coronavirus SARSCoV-2 that was first identified in Wuhan, China 2019 and that led to a worldwide pandemia [1]. The WHO has declared the outbreak of SARS-CoV-2 infection an international public health emergency. The disease is caused by a enveloped, non-segmented positive-sense $\beta$ RNA coronavirus. The term corona derives from the Latin word "corona" that means "crown" and that describes the appearance of the virus by electron microscopy [2].

COVID-19 is clinically characterized by a presentation ranging from the common cold to severe respiratory disease and death. Human-to-human transmission occurs mainly through the respiratory tract, by droplets, respiratory secretions, and direct contact. The presence of SARSCoV-2 in fecal swabs or blood indicate the multiple transmission routes of this infection. Typical manifestations of COVID-19 include fever, sore throat, shortness of breath and cough [3]. However, many patients show extrapulmonal symptoms including myalgia, headache or diarrhea. In the recent publication by Zhou $\mathrm{Z}$ et al. [4] including 254 patients with SARS-CoV-2 infection, $83 \%, 38,6 \%$ and $26 \%$ complained of fever, cough and gastrointestinal symptoms, respectively. The mortality rate ranges from $1-10 \%$ due to the development of fatal pneumonia. Patients with comorbidities such as hypertension, diabetes and coronary heart disease have a significantly poorer clinical outcome. The disease may lead to a number of complications such as acute respiratory distress syndrome (ARDS), arrhythmia, shock, acute kidney injury, acute cardiac decompensation, liver dysfunction or secondary infections. The diagnosis is based on the nucleic acid identification of SARS-CoV-2 by real-time PCR. Due to the lack of an effective antiviral therapy, the treatment of this disease is mainly focused on symptomatic and respiratory support. Recently, an antiviral therapy with remdesvir and chloroquine (originally used to treat malaria) is investigated in several studies [5].

\section{COVID-19 AND GASTROINTESTINAL MANIFESTATIONS}

The presence of gastrointestinal symptoms (vomiting, diarrhea, nausea or abdominal discomfort) indicates a possible spread of the virus via the gastrointestinal tract. Interestingly, Chen $\mathrm{L}$ et al demonstrated recently the presence of SARS-CoV-2 in the fecal specimens of a patient with negative results on multiple pharyngeal and sputum samples [6]. This important observation indicates that the virus may proliferate in the gastrointestinal tract and patients with gastrointestinal symptoms should be screened for COVID-19. Moreover, the presence of the virus in the gastrointestinal tract represents a possible threat for the endoscopist [7].

\section{COVID-19 AND LIVER}

The infection with SARS-CoV-2 may be accompanied by the presence of elevated aminotrasferases as shown in our 7 patients The results are: Pt 1 - age 47; ASAT/ GOT (range: $0,17-0,85 \mu \mathrm{kat} / \mathrm{l}$ ) 1,1; ALAT/GPT (range: $0,17-0,83 \mu \mathrm{kat} / \mathrm{l}$ ) 1,04; Gamma-GT (range: 0,17 - 1,19 


\section{Risk stratification for SARS-CoV-2 in patients undergoing endoscopic procedures}

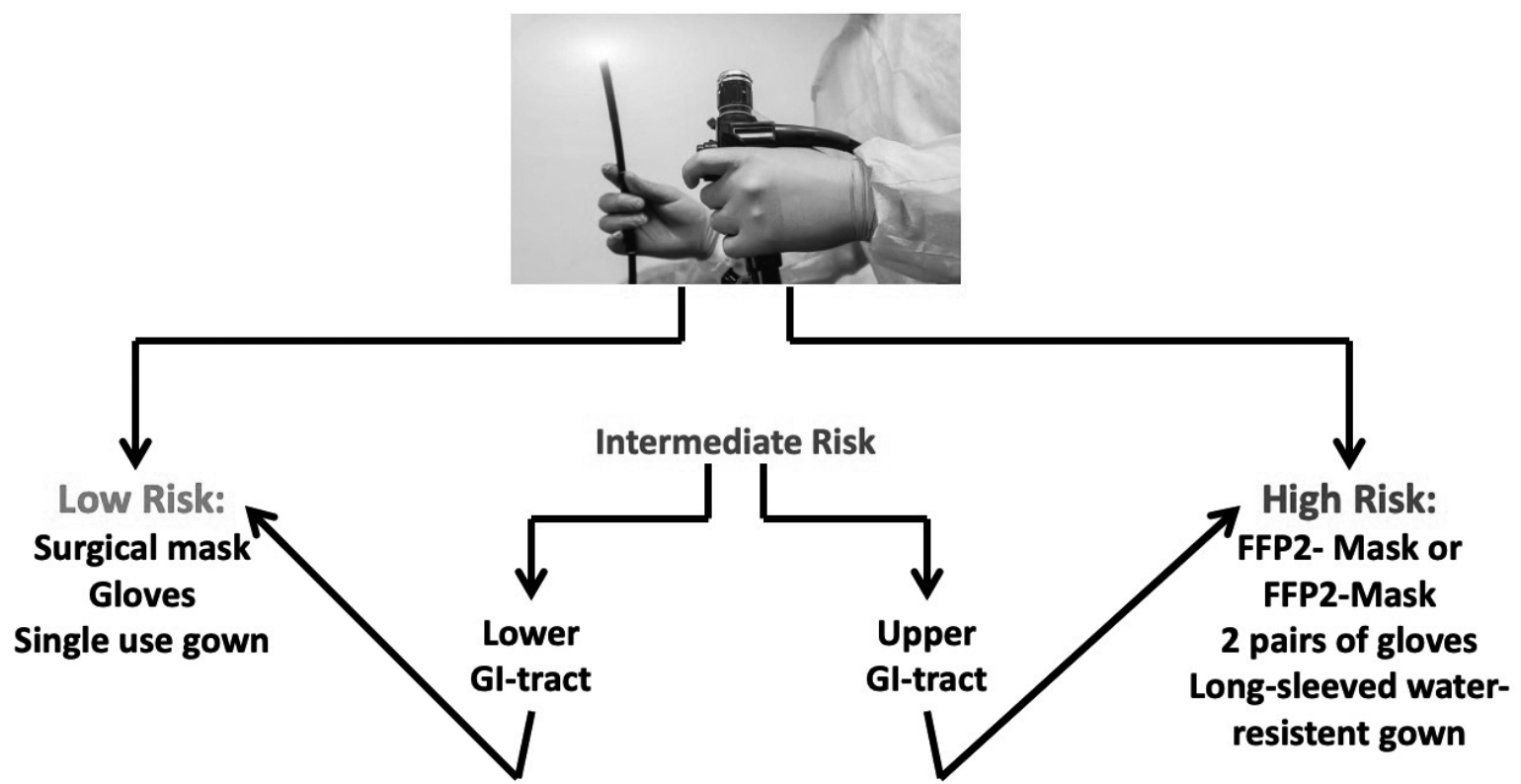

Fig 1. Risk stratification (low, intermiediate and high risk) for SARS CoV-2 in patients undergoing endoscoping procedures. FFP - filtering face peace.

$\mu$ kat/l) 1,19; Bilirubin (range: $<17 \mu \mathrm{mol} / \mathrm{l}$ ) 6,67; Pat. 2 age 59 ASAT/GOT (range: 0,17 - 0,85 $\mu \mathrm{kat} / \mathrm{l}$ ) 2,48, ALAT/ GPT (range: 0,17 - 0,83 $\mu \mathrm{kat} / \mathrm{l}$ ) 5,17, Gamma-GT (range: 0,17 - 1,19 $\mu \mathrm{kat} / \mathrm{l}$ ) 1,95, Bilirubin (range: $<17 \mu \mathrm{mol} / \mathrm{l}$ ) 8,90; Pat. 3 age 46 ASAT/GOT (range: 0,17 - 0,85 $\mu \mathrm{kat} / \mathrm{l}$ ) 0,62, ALAT/GPT (range: 0,17 - 0,83 $\mu \mathrm{kat} / \mathrm{l}$ ) 0,25 Gamma-GT (range: $0,17-1,19 \mu \mathrm{kat} / \mathrm{l}$ ) 0,48, Bilirubin (range: $<17$ $\mu \mathrm{mol} / \mathrm{l}$ ); Pat. 4 age 64 , ASAT/GOT (range: $0,17-0,85$ $\mu \mathrm{kat} / \mathrm{l}$ ) 1,39, ALAT/GPT (range: 0,17 - 0,83 $\mu \mathrm{kat} / \mathrm{l}$ ) 0,89 Gamma-GT (range: 0,17 - 1,19 $\mu \mathrm{kat} / \mathrm{l}$ ) 0,42, Bilirubin (range: $<17 \mu \mathrm{mol} / \mathrm{l}$ ) 10,20; Pat. 5 ASAT/GOT (range: 0,17 - 0,85 $\mu \mathrm{kat} / \mathrm{l}$ ) 0,52, ALAT/GPT (range: 0,17 - 0,83 $\mu \mathrm{kat} / \mathrm{l}$ ) 0,89 Gamma-GT (range: 0,17 - 1,19 $\mu \mathrm{kat} / \mathrm{l}$ ) 2,40, Bilirubin (range: $<17 \mu \mathrm{mol} / \mathrm{l}$ ) 7,36; Pat. 6 age 46 , ASAT/GOT (range: 0,17 - 0,85 $\mu \mathrm{kat} / \mathrm{l}$ ) 0,62, ALAT/GPT (range: 0,17 - 0,83 $\mu \mathrm{kat} / \mathrm{l}$ ) 0,43, Gamma-GT (range: 0,17 - 1,19 $\mu \mathrm{kat} / \mathrm{l}$ ) 1,42, Bilirubin (range: $<17 \mu \mathrm{mol} / \mathrm{l}$ ) 13,3; Pat. 7 65, ASAT/GOT (range: $0,17-0,85 \mu \mathrm{kat} / \mathrm{l}$ ) 1,48, ALAT/GPT (range: 0,17 - 0,83 $\mu \mathrm{kat} / \mathrm{l}$ ) 0,94 Gamma-GT (range: 0,17 - 1,19 $\mu \mathrm{kat} / \mathrm{l}$ ) 3,83 , Bilirubin (range: $<17 \mu \mathrm{mol} / \mathrm{l}$ ) 11,99. Importantly, the development of severe liver injury is uncommon. The differential diagnosis of increased liver aminotransferases include the hepatitis induced by virus, drug-induced liver disease and liver complications due to sepsis [8]. Huang et al demonstrated that the incidence of abnormal levels of asparate and aspartate aminotrasferase (ALT, AST) is more frequently in patients with severe diseases, especially in those patients that require therapy in the intensive care unit (ICU). Hepatic dysfunction in patients with severe
COVID-19 is accompanied by activation of fibrinolytic and coagulative pathways and increased ferritin levels in the blood [9]. This observation implicates that patients with chronic liver diseases are at higher risk of development of significant liver injury due to COVID-19 infection. However, the data on the effect of SARS-CoV-2 infection in patients with chronic liver diseases is very limited.

\section{COVID-19 AND INFLAMMATORY BOWEL DISEASE}

Patients with inflammatory bowel disease (Crohn's disease, ulcerative colitis) treated with corticosteroids, biologic or immunosuppressive agents are more susceptible for infections. Especially biologicals targeting tumor necrosis factor alpha such as infliximab, adalimumab, certolizumab or biosimilars as well as Janus kinase (JAK) inhibitors like tofacitinib show a significantly increased risk for serious infections. Compared to other therapeutic regimens, these drugs increase the risk for different viral infections such as herpes simplex virus, varicella zoster virus, cytomegalovirus infection or hepatitis $B$ reactivation. Age represents an important independent risk factor for opportunistic infections in IBD patients [10, 11]. Considering the risk for infections, both vedolizumab and ustekinumab have a much better safety profile [12]. In the literature, no case of an IBD patient and SARS-CoV-2 infection was reported so far, so the information on that issue is lacking. The Chinese Society of IBD made some recommendations for managing patients with IBD during 
the COVID-19 pandemia [13]. Generally, patients with IBD show a number of risk factors for severe course of SARS$\mathrm{CoV}-2$ infection such as therapy with corticosteroids and other immunosuppressive agents, malnutrition, frequent visiting of the hospital, comorbidities (hypertension, diabetes) and pregnancy. Based on the observation made during epidemia in Wuhan, the experts recommend to continue current treatment, given, the disease is stable. The therapy with vedolizumab or ustekinumab should be considered as a first line therapy due to their good safety profile, if a new therapy is started. Tofacitinib should not be newly prescribed, because this drug significantly increases the risk for viral infections (especially varicella zoster virus). During the pandemia, only emergency endoscopy should be performed. Elective endoscopy should be postponed. Every patient that needs emergency surgery should be screened for COVID-19. Patients with acute fever should immediately consult their IBD doctor.

\section{COVID AND ENDOSCOPY}

Patients scheduled for an endoscopic procedure need to be stratified individually according to risk of COVID-19 (low risk, intermediate and high risk) (Fig. 1). Low risk patients undergoing the endoscopic procedure show no symptoms of COVID-19 (cough, fever, shortness of breath), no contact to SARS-Cov-2 positive person(s) and nonstay in high risk areas for COVID-19 in the last 14 days. Patients at intermediate risk may show symptoms (cough) but no medical history for contact with SARS-CoV-2 positive person or stay in a high-risk area. Patients with no symptoms, but medical history of the contact with SARS-CoV-2 positive person or stay in high risk area are also at intermediate risk. Finally, high risk patients include patients with at least one typical COVID-19 symptom (cough, breathlessness, fever) and contact to SARS-CoV-2 positive person(s) or a stay in a high risk area in the last 14 days. All patients entering the endoscopy unit should wear a surgical mask. Endoscopy personnel should reduce exposure hazards by keeping a distance from the patient and using gloves, face masks (in case of high risk patients FFP2 or FFP3 masks), face shields and gowns [14].

\section{COVID AND FECAL MICROBIOTA THERAPY (FMT)}

Clostridium difficile represents the most common healthcare associated infection worldwide. Recurrences of this disease are clinically challenging and even prolonged antibiotic therapy may be not effective [15]. Repeated antibiotic therapy has a negative impact on the gut microbiota diversity and thus increases the risk for further overgrowth of $C$. difficile and the probability of CDI reccurences. The only way to break this circulus vitiosus seems to be the restoration of gut microbiota with fecal microbiota transplantation (FMT). FMT is an emerging therapy for CDI that offers the potential for a rapid and lasting elimination of the infection through restoration of healthy microbiota.
FMT is a process of stool transfer from one or multiple healthy donors to the gut of the sick person [16]. For FMT, fresh, frozen lyophilized, and capsule-based formulation can be used. The fecal microbiota transfer is performed by colonoscopy, nasogastric tube or capsules. Due to the SARS-CoV-2 outbreak, special attention should be given to FMT donors and stool banking. To prevent SARS-CoV-2 transmission, every donor should be screened for the presence of typical COVID-19 symptoms (fever, fatigue, maylgia, dry cough, dyspnea and headache). In addition, the donor's travel to regions affected by COVID-19 or close contact to individuals with proven or suspected SARS-CoV-2 infection within recent 30 days should be questioned [17]. Due to the fact, that some patients show only an evidence of SARS-CoV-2-infection in stool probes, but no symptoms of an infection in the respiratory tract, every donor should additionally get a pharyngeal swab and have a testing of the stool probe for the presence of the virus done. FMT from multiple donors should be avoided.

The Federal Institute of Drugs and Medical Devices (BFARM) in Germany in the recent statement released on 1st April 2020 recommends the suspending of FTM procedure during the COVID-19 pandemia to minimize the risk of SARS-CoV-2 transmission. The only exception should be the cases of recurrent and treatment-resistant C. difficile infection. In such justified cases, the FMT using stool obtained before 1.1.2020 should be used.

\section{REFERENCES}

1. Zhu N, Zhang D, Wang W, et al. China Novel Coronavirus Investigating and Research Team. A Novel Coronavirus from Patients with Pneumonia in China, 2019. N Engl J Med. 2020; 382 (8):727-733. doi: 10.1056/ NEJMoa 2001017.

2. Lu R, Zhao X, Li J, et al. Genomic characterisation and epidemiology of 2019 novel coronavirus: implications for virus origins and receptor binding. Lancet. 2020;395(10224):565-574. doi: 10.1016/50140-6736 (20) $30251-8$.

3. Guo YR, Cao QD, Hong ZS, et al. The origin, transmission and clinical therapies on coronavirus disease 2019 (COVID-19) outbreak - an update on the status. Mil Med Res. 2020;7 (1):11. doi: 10.1186/s40779-02000240-0.

4. Zhou Z, Zhao N, Shu Y, Han S, Chen B, Shu X. Effect of gastrointestinal symptoms on patients infected with COVID-19. Gastroenterology. 2020 Mar 18. pii:S0016-5085(20)30362-0. doi:10.1053/j.gastro.2020.03.020.

5. Wu D, Wu T, Liu Q, Yang Z.The SARS-CoV-2 outbreak: what we know. Int J Infect Dis. 2020 Mar 11. pii:S1201-9712(20)30123-5. doi: 10.1016/j. ijid.2020.03.004.

6. Wu D, Wu T, Liu Q, Yang Z. COVID-19 Disease with positive fecal and negative pharyngeal and sputum viral tests. Chen L, Lou J, Bai Y, Wang M. Am J Gastroenterol. 2020 Mar 20. doi: 10.14309/ ajg.0000000000000610.

7. Ong J, Young BE, Ong S. COVID-19 in gastroenterology: a clinical perspective. Gut. 2020 Mar 20. pii: gutjnl-2020-321051. doi: 10.1136/ gutjnl-2020-321051.

8. Bangash MN, Patel J, Parekh D. COVID-19 and the liver: little cause for concern. Lancet Gastroenterol Hepatol. 2020 Mar 20. pii: \$2468-1253 (20) 30084-4. doi: 10.1016/S2468-1253(20)30084-4. 
9. Huang C, Wang Y, LiX, et al. Clinical features of patients infected with 2019 novel coronavirus in Wuhan, China.Lancet. 2020;395(10223):497-506

10. Kordzadeh-Kermani E, Khalili H, Karimzadeh I, Salehi M. Infect Drug Resist. 2020;13:513-532. doi: 10.2147/IDR.S233137. eCollection 2020. Prevention strategies to minimize the infection risk associated with biologic and targeted immunomodulators.

11. Lin E, Lin K, Katz S. Serious and opportunistic infections in elderly patients with inflammatory bowel disease. Gastroenterol Hepatol (N Y). 2019;15(11):593-605

12. Pudipeddi A, KariyawasamV, Haifer C, Baraty B, Paramsothy S, Leong RW. Expert safety of drugs used for the treatment of Crohn's disease. Opin Drug Saf. 2019;18(5):357-367. doi: 10.1080/14740338.2019.1612874. Epub 2019 May 6.

13. Mao R, Liang J, Shen J, Ghosh S, Zhu LR, Yang H, Wu KC, Chen MH. Chinese Society of IBD, Chinese Elite IBD Union, Chinese IBD Quality Care Evaluation Center Committee. Lancet Gastroenterol Hepatol 2020;2020 Mar 11. pii: S2468-1253(20)30076-5. doi: 10.1016/S24681253(20)30076-5.

14. Repici A, Maselli R, Colombo M, et al. Coronavirus (COVID-19) outbreak: what the department of endoscopy should know. Gastrointest Endosc. 2020 Mar 13. pii: S0016-5107(20)30245-5. doi: 10.1016/j. gie.2020.03.019.

15. Orenstein R, Patron RL. Clostridioides difficile therapeutics: guidelines and beyond. Ther Adv Infect Dis. 2019 Aug 13;6:2049936119868548. doi: 10.1177/2049936119868548.

16. KonturekPC, Koziel J, DieterichW, HaziriD, WirtzS, Glowczyk I, KonturekK. Neurath MF, ZopfY. Successful therapy of Clostridium difficile infection with fecal microbiota transplantation. J Physiol Pharmacol 2016; 67(6):859-866
17. Ianiro $G$, Mullish BH, Kelly $C R$, et al. Screening of faecal microbiota transplant donors during the COVID-19 outbreak: suggestions for urgent updates from an international expert panel. Lancet Gastroenterol Hepatol. 2020 Mar 16. pii: S2468-1253(20)30082-0. doi: 10.1016/ S2468-1253(20)30082-0

\section{ORCID and contributionship}

Peter Christopher Konturek A,B,D,E,F

Igor Alexander Harsch - 0000-0003-2716-0066 A,B,D,E,F

\section{Conflict of interest}

Authors declare no conflict of interest

\section{CORRESPONDING AUTHOR} Peter Christopher Konturek

Dept. of Medicine II, Thuringia-Clinic Saalfeld, Teaching Hospital of the University of Jena

e-mail:pkonturek@web.de

Received: 26.03 .2020

Accepted: 10.04 .2020 